http://spilplus.journals.ac.za/

\title{
TRANSLATING CULTURE-BOUND WORDS: A PROBLEM IN BILINGUAL LEXICOGRAPHY
}

\author{
Maria Smit, Department of School Music, University of Stellenbosch
}

\section{Introduction}

Translators often have problems when they have to translate culture-specific words. These words very often do not have adequate translation equivalents in the target language. In this paper, this problem is addressed from a semantic point of view, using Menachem Dagut's classification of semantic voids as a theoretical framework. The aim is to contribute to one of the topical questions discussed at this conference, namely: "What does linguistics offer the language professions?" Reformulated, the question could read: "What does semantic investigation offer translators and lexicographers of bilingual dictionaries?"

\section{Dagut's classification of semantic voids}

Dagut has made an in-depth study of one specific translation problem, namely, the problem associated with the translation of culture-bound words. He $(1978,1981)$ analyzes examples of English translations of Hebrew texts. In so doing, he (1978:14) attempts to illuminate the processes taking place, in order to "enable the Heb.-Eng, translator to attain a better and deeper understanding of his difficulties and to suggest to him ways of improving his performance." Dagut does not claim that his classifications form a comprehensive translation theory.

According to Dagut (1981:63), human beings use words to classify their experiences which arise from external sensory impressions or inner emotions and thoughts. Human experience, however, can differ almost infinitely in variety and detail. Therefore, in expressing themselves, speakers usually only select a very few of all the possible features of their experience, to the exclusion of all others. Without such a drastic selection, the vocabulary of any language would expand far beyond the "storage and recall capacity of the ordinary human mind", as Dagut (1981:63) puts it. He (1981:63, note 8) quotes Sapir on this point: "The world of our experience must be enormously simplified and generalized before it is possible to make a symbolic inventory of all our experiences of things and relations and this inventory is imperative before we can convey ideas." 
http://spilplus.journals.ac.za/

Dagut (1981:63) figuratively describes the vocabulary of a language as a "kind of shared 'map' of its speakers' experiences." This "map" locates all the items in the vocabulary of that particular language. In Dagut's (1981:63) terminology, the "collective consciousness" of the language-community as a whole selects certain "salient features" from each experience. Specific designatory terms are then assigned to mark such salient features. These designatory terms or designators are defined by Dagut (1981:62) as "patterns of phonemes baving referential function, whether the reference is 'concrete' (book, run, white), 'abstract' (truth, believe, pleasant), or merely purported (fairy, utopia, tomomow)." Such designators refer to specific extralingual entities. According to Dagut (1981:62), they also perform a symbolic function by encapsulating within their "sound envelope" a whole complexity of situational features. These situational features are the above-mentioned "salient features" of human experience. 1)

According to Dagut (1981:63), the figurative lexical "map" of every language will have many "blank spaces". These "blank spaces" occur for several reasons. In the first place, they occur where there is no need to find a designator, because a particular experience does not exist in a specific language-community. Secondly, "blank spaces" occur because each particuar language is "ignoring or giving prominence to different aspects of 'reality", in Dagut's (1978:45) opinion. It appears to him (1978:45-46) that "...the 'words' of a language are inmediately recognizable indications of the features of experience which are of primary concern to the speakers of that language..."

The blank spaces on the lexical "map" of one language will not, in most cases, coincide with the blank spaces on the lexical "map" of another language, in Dagut's (1981:63) view. Languages differ in their lexical selections, just as they differ in their phonological and syntactical structures. The translation problem caused by this difference in the lexical mapping of languages is Dagut's main concern. He does not investigate the "blank spaces" as such, but the "voids" resulting from the blank spaces which are revealed during the translation process when two languages are compared.

Dagut (1978:45) defines such semantic voids as "the non-existence in one language of a one-word equivalent for a designatory term found in another". Semantic voids are usually found on the level of the individual word, Dagut (1981:63) asserts. This means that a semantic voids exists when there is no single target language word to convey the meaning of a particular source language word. To illustrate this point, Dagut (1981:64, note 9) quotes 
http://spilplus.journals.ac.za/

360

Rabin (1958:127): "Of course, all...concepts can be expressed in the languages which do no possess words for them, but only as phrases..." This means that, in the target language, more than one lexical item (or a periphrastic rendering) has to be used to symbolize the same selected features of experience encapsulated by the one-word lexical source language item. Therefore, a particular language A may be "better equipped" to express something than another language B, Dagut (1981:64) claims. He (1978:46) states: "It may be assumed that what is described in any language only by periphrastic means... does not occupy a centrally significant place in the awareness of 'reality' possessed by the speakers of that language."

\section{Types of semantic voids}

Dagut (1981:64-69) distinguishes between two basic types of semantic voids: referential and linguistic voids. He also identifies several means of transfer which can be used to solve the translation problem caused by each type of semantic void. Different types of equivalence may result. He deals mainly with denotational and connotational equivalence. He also deals with cultural equivalence and communicative equivalence, which can be placed under the heading connotative equivalence, although he does not use the expression communicative equivalence. In this paper, I shall concentrate mainly on referential voids, the means of transfer which can be used in the case of such voids, and the extent to which denotational and connotational equivalence can be achieved.

\subsection{Referential voids}

Referential voids are a result of extra-linguistic factors, according to Dagut. He (1981:64) refers to Rabin (1958:127), who describes referential voids as "blank spaces in the field of reference, corresponding to referents outside the ken of the language-community." Dagut (1978:89) states that a referential void is untranslatable, "unless and until the referent is added to the conceptualized experience" of the target language speakers.

There are two types of referential voids, according to Dagut (1978:48-65), namely, environmental and cultural voids.

The category of environmental voids is determined by the conditions in the environment in which language-communities live. Certain natural phenomena, animals, plants, etc. which are part of the environment of one language-community may be absent from the 
http://spilplus.journals.ac.za/

361

environment of another. In English, for example, an environmental void corresponds with hamsin, because this term designates a specific climatic phenomenon in Israel: it is the name given to a bot wind which blows from time to time. The word is "part of the ordinary Israeli's everyday usage", according to Dagut (1978:174, note 21). Speakers of English, however, do not normally experience this climatic phenomenon, and therefore do not have a designator to symubolize this experience.

Cultural terms, 2 ) on the other hand, denote customs peculiar to specific languagecommunities, such as religious ceremonies.

Dagut (1978:52) claims that environmental voids are not as "translation-resistant" as cultural voids. The reason for this is that it is far easier for the average speaker to transcend the limits of his or her mother tongue geographically and climatically than culturally. Culturally, people tend to abide by their own customs and concepts. It appears to Dagut (1978:52-53) that people show only a "superficial and rather incredulous interest in other cultures." They are not in the least interested in linguistic encroachment on the part of foreign cultures. Therefore, a large-scale adoption of cultural terms by one language implies a certain measure of absorption of the culture of another community.

To illustrate his notion of referential void, Dagut (1981:64) uses several examples. Only two examples will be discussed here. The first is the Hebrew word, ma'pil, to which a semantic void corresponds in English. The situational features of this word ate immigrant to Israel + time of British Mardate + so-called illegal.3) There is no one-word designator in English which can convey the entire semantic content of this Hebrew word. One could periphrastically render the meaning of ma'pil as a so-called illegal immigrant in the time of the British Mandate. This adequately expresses the semantic content of the Hebrew word, but there is an evident loss of compression. According to Dagut (1981:61), this periphrastic rendering is "a loose explanation rather than an effective translation." This is so, because the replacement of a source language designator by a target language periphrasis "results in a marked change in the status of the symbolized experience in the consciousness of the speakers of the two languages." $M a^{\prime}$ pil is a historical word which occupies a "well-defined place in the national awareness and emotions of Hebrew speakers", Dagut (1981:64) asserts. The English periphrastic rendering does not have the same historical and emotional status in the consciousness of English speakers. So, although the periphrasis may be denotatively equivalent to the source language word, it lacks connotative equivalence. 
http://spilplus.journals.ac.za/

Therefore, the periphrastic English rendering is not an effective translation of the one-word designator ma'pil and consequently, a semantic void corresponds to maipil in English.

In another example, Dagut (1978:54) analyzes a translation of the word quorum, which is used in a religious sense as well as a secular sense in Hebrew. In its religious sense, it denotes "a quorum of ten males for prayer", but in its secular sense, it denotes "any quorum whatsoever." When religious terms are used in their religious sense, target-language readers will be unable to interpret such terms correctly unless they are acquainted with the religious customs symbolized by the terms. If the Hebrew word quorum is used in its religious sense in the context of a marriage ceremony, as it is done in Dagut's example, additional explanatory notes would be necessary to introduce target-language readers to the exact circumstances of the religious ceremony symbolized by the term in question.

\subsection{Linguistic voids}

Linguistic voids are caused by intra-linguistic factors, which means that although different languages may have the same referents in their extra-linguistic reality, they have different ways of symbolizing these shared referents. The way in which situational features of experience are selected and organized differ from one language to another. For example, Dagut (1981:64-65) states that in English, a linguistic void corresponds to the Hebrew word silsom (=the day before yesterday). The referent does exist in the experience of English speakers, but the "particular lexical capsule", to use Dagut's (1981:65) terminology, does not exist in English. Therefore, in English, more than one lexical item is used to denote the same referent.

\section{Means of transfer in the case of referential voids}

On the basis of his analyses of Hebrew-English translations, Dagut (1981:66) concludes that, in the case of referential voids, two distinct means of transfer can be identified. These are transcription and translation proper. A third means, namely, explanation, can also be used in combination with both transcription and translation proper.

\subsection{Transcription}

A translator may use transcription when a target language does not have a designator which could serve as a translation equivalent for the word used in the source language. 
http://spilplus.journals.ac.za/

363

Dagut (1978:173, note 17) explains that, in this case, a translator tries to represent in the target language the sound pattern which was used in the source language. A source language word is inserted into the target language text, taking into consideration the phonological system of the target language. Usually, italics or inverted commas are used, to indicate that a "foreign body" has been inserted into the target language. Once a referent is sufficiently well-known to speakers of the target language, the foreign word may be incorporated into the vocabulary of that language. The italics or inverted commas can then be omitted. The word wadi, for example, was originally an Arabic word. It denotes a watercourse in North Africa and Arabia, dry except in the rainy season. It has been incorporated into Hebrew, and it also is included in an English dictionary such as Collins Dictionary of the English Language, even though it still has a "foreign flavour", to use Dagut's (1978:51) terminology.

Dagut $(1978: 51,57)$ takes transiription to be the best means of transfer in the case of referential voids. Transcription, however, should always be accompanied by "an adequate explanatory footnote or glossary entry", according to Dagut (1978:57). Without such an explanatory note, the source language term used in the target language will be "totally meaningless" to a target language reader. Once the target language reader knows what the transcribed term means, the term can be used throughout the rest of the text without explanation.

To Dagut (1978:57), transcription, supplemented by an explanatory note, has the advantage of "complete cultural accuracy." When transcription is used without an explanatory note, however, there is neither denotational nor connotational equivalence between source language and target language items. Although the translation may be accurate, in the sense that it contains the same situational features, it is non-informative to target language readers. Target language readers cannot deduce the meaning of an unknown source language word from the context as such without an explanatory note. Therefore, the target language rendering will neither be denotatively, nor connotatively equivalent to the original source language version.

With transcription, supplemented by an adequate explanatory note, there is no danger of evoking the wrong associations, and no depletion of the semantic content of the source language term. Such wrong associations and depletion might occur when a translator tries to merely translate a term. 
http://spilplus.journals.ac.za/

\subsection{Translation proper}

To illustrate the problem of translating culture-bound words by means of translation proper, Dagut (1978:54) discusses words referring to the Jewish marriage ceremony. He (1981:66) claims that the referents present in the Jewish marriage ceremony, to which the Hebrew terms refer, do not exist in the "experience and lexical classifications of native English speakers." In English, referential voids correspond to such culture-specific terms.

Dagut (1978:54) contends that when translators use translation proper as a means of rendering, they "content themselves with translating the non-specific content of the passage." An example is the rendering The mariage was performed in the yard of the Rabbinate. Although target language terms such as marriage and yard are immediately intelligible to target language readers, Dagut (1978:55) states that this translation "depletes the original by omitting all reference to one of the main ritual features of the Jewish marriage ceremony." English seaders are accustomed to the idea of people getting married in "some kind of an office", so that getting married in a yard may sound somewhat confusing. The English term marriage does not convey any information about the exact circumstances of a Jewish marriage ceremony.

Therefore, Dagut (1981:66) argues that, in the case of referential voids, translation proper sesults in inaccuracy, because of the depletion of the semantic content of source language terms. Translation proper, in this instance, results in the lack of denotational equivalence, because all the situational features of the source language term are not rendered by the translation equivalents in the target language. It also results in the lack of connotational equivalence because the emotional or religious status the Hebrew word has in the consciousness of Hebrew speakers is not reflected in the target language rendering.

\subsection{Explanation}

Dagut (1981:67) uses the expression periphrastic rendering to denote the explanation of a source language term by means of a paraphrase in the target language. An explanation can, as has already been sajd, be combined with other means of transfer, for example, with transcription or translation proper. According to Dagut (1978:65), an explanation should always be marked as such. It should, also, give accurate information on the source language item which is not conveyed by the transcription or translation proper. 
http://spilplus.journals.ac.za/

\section{An analysis of the German word Volk}

When I analyzed translations of Hitler's work Mein Kampf $(1939), 4)$ it became clear that translators experienced tremendous difficulties in translating National Socialist ideological words into a language such as English. Although it is not possible to give a detailed account of the analyses, I shall show that the bilingual dictionaries I consulted were not very helpful to solve the translation problems at hand.

One example is the word Volk, as Hitler used it. One translator, Manheim (1969), has had to resort to no fewer than three different renderings of Volk, aamely, people, race and nation in his translation of Mein Kampf.5)

This problem is caused by what Dagut (1981:64) describes as "a marked change in the status of the symbolized experience in the consciousness of the speakers of the two languages" at hand. Because speakers of the target language have not had exactly the same experience as the source language speakers, they are not in a position to select "certain salient features" of that experience to symbolize it by means of a designator. Speakers of other languages, for example, did not exactly experience the same nationalist feelings as the Germans did during the Nazi period. Therefore, the emotive value of utterances such as those made by Hitler cannot have the same effect on foreigners as they had on Germans living in Germany at that time, unless the emotive force of the words is explained to them. Hitler's writings and speeches were meant for Germans. He wished to inspire them for Nazi ideology. A translation of a text such as Hitler's Mein Kampf can never have the same effect on readers living under different circumstances and in different times.

\subsection{The semantic features of Volk according to some monolingual German dictionaries}

From monolingual German dictionaries such as the DrV-Lexikon and Trübner, it becomes clear that the word Volk can be used in two main senses, namely, a more general sense and a more specific sense. In the first sense, Volk can be equated with nation because it denotes any nation which has a common spiritual and cultural development and usually a common language, and which strives towards political unity. The following situational features could be attributed to Volk in this first sense: 
http://spilplus.journals.ac.za/

people usually sharing the same language + people sharing the same culture + people sharing the same history + people sharing the same spiritual development.

According to the two above-mentioned dictionaries, the word Volk was used in a second, more specific, sense during the German Romantic period in the 19th century. Trubner mentions, amongst other things, that in the writer Herder's works, the word Volk can be found in compounds such as Volksseele and Volkscharakter, which were used to express nationalist feelings. At the beginning of the 19th century, the loan word Nation was adopted. Nation, however, denoted a politically unified nation of people, and could not, therefore, be equated with Volk, which denoted the German people who were, at that stage, not a politically unified nation. Later on, Jahn, Arndt and the writers of the Romantic period used the word Volk in the nationalist sense of a unified German nation. The situational features of Volk, in this sense, could, therefore, be presented as follows:

a politically unified nation or a nation striving towards political unity + a nation which feels politically unified.

Other monolingual dictionaries which I have consulted, such as Wahrig and Duden, do not give any information on the different uses of Volk.

Studies on Nazi language usage, on the other hand, do provide information on the different uses of Volk. For example, studies such as those by Berning (1961:107) and Hammer (1974:27) indicate that before and during the Nazi period the word Volk also acquired the situational features superior people + people chosen to uphold racial purity + people sharing nationalist feelings. From this, one can deduce that the denotation of the word Volk during the Nazi period differed from its denotation before that period.

In addition, the connotational meaning of Volk gradually changed, due to the surge of strong Nationalist feelings in the German nation. Seidel and Seidel-Slotty (1961:91) state that Volk was used by politicians as an ideological term to arouse strong nationalist feelings in the German people. It seems that the connotative meaning of Volk became more important than its denotative meaning. Consequently, a shift occurred in the connotational meaning of Volk. 
http://spilplus.journals.ac.za/

367

These shifts in the denotational and connotational meanings of Volk are not reflected in the monolingual dictionaries which $\mathrm{I}$ have consulted.

5.2 The semantic features of Volk according to some bilingual dictionaries

Some Getman-English dictionaries present the following infonnation on Volk:

Wildhagen-Héraucourt: "a people/nation/men, troops, soldiery/crew"

Muret-Sanders: "1) people 2) people, nation 3) set, lot, 4) servants 5) men (army) 6) troops, flock, flight";

Langenscheidts: "1) (Nation, Land) people, nation 2) <only sg.> (Bevölkerung) people 3) <only sg. > (Menschen) people 4) (Klasse) class 5) <only sg.> (Masse, Menge) mass(es pl.) of people, crowds 6) < only sg.> (contempt.) mob, lot, crowd (colloq.) 7a) (von Bienen): swarm b) (von Rebhühnern) covey c) (von Wachteln) bevy."

None of the bilingual dictionaries I have consulted, gives any information on the shifts in meaning of the word Volk before and during the Nazi period. Although Langenscheidts gives the most elaborate exposition of the different uses of Volk, still only the more general senses of Volk are dealt with. Nothing is said of Volk within the specific context of Nazi ideology.

\section{Conclusion}

If bilingual dictionaries are to be of any assistance to translators in the translation of words in their specialized, culture-bound sense, such dictionaries will have to present more adequate semantic information. Given Dagut's classification of types of equivalence, bilingual lexicographers could, for example, present the following information in the case of Volk:

In addition to the translation equivalents people/nation, an explanatory note should be added indicating the full range of distinct contexts in which the word Volk can be used. For example, the context in which Volk is used in its non-specialized sense, and the context in which it is used in its specialized, National Socialist sense, could be specified. 
http://spilplus.journals.ac.za/

In addition, relevant shifts that the meaning of Volk has undergone should also be specified. These indications could include some encyclopedic information about the Nazi usage of Volk or, alternatively, a presentation of the situational features of Volk in its culture-bound sense.

To conclude, translators and bilingual lexicographers can use Dagut's classification of types of semantic voids, means of transfer and types of equivalence as a framework for determining and describing the semantic content of source language words and expressions, for choosing the most adequate means of transfer, and for establishing different types of equivalence.

Dagut's models, however, need to be worked out in more detail. I shall make only a few suggestions in this regard: In further inquiry, for example, his classifications should be applied to translations in other pairs of typologically and genetically unrelated languages. Dagut's analyses are not always sensitive to the fact that words may have different senses in different contexts, and that words undergo shifts in meaning in the course of time.

All in all, however, it is clear that the conceptual distinctions drawn by Dagut's classification of semantic voids can contribute in a significant way to the compilation of better bilingual dictionaries.

NOTES

1. Dagut (1978:167, note 6) states that he is not interested in the problem of whether socalled "structural' words (e.g. is, but, off, not, etc.)" have referential meaning. He is only interested in "designators' (or 'content words')."

2. Dagut (1978:53-65) even divides the category of cultural terms into two subcategories. These are religious and secular terms. Semantically, however, these terms present the same translation problems, so that this distinction will not be discussed in detail in this paper.

3. Dagut (1978:176-177, note 35) states that he does not attempt to make a rigorous "componential" analysis of the words he investigates. He does not use the formal methods which are sometimes used in contrastive analysis, and he deliberately avoids the term component as it is sometimes used in contrastive analysis. Dagut (1978:177, note 35) 
http://spilplus.journals.ac.za/

369

explains that he regards semantic features as "informal descriptions of the situational conditions \{and he quotes Bendix (1966:35, note 6) - M.S.\} 'which must be fulfilled if an occurrence of the form is to denote properly"."

4. For a detailed analysis of some of Hitler's utterances in terms of semantic voids, cf. Smit (1990).

5. Another translator, Baynes (1942:v), notes that "many of the National Socialist-keywords do not really admit of any satisfactory English rendering; words have their own atmosphere, and that atmosphere is lost by a transference to another language."

\section{BIBLIOGRAPHY}

Baynes, N.H. 1942. The speeches of Adolf Hitter: April 19.22- August 1939. Vols I and II. London: Oxford University Press.

Bendix, E.H. 1969. Componential analysis of general vocabulary. Bloomington: Indiana University.

Berning, C. 1961. "Die Sprache des Nationalsozialismus", Zeitschrift für deutsche Wortforschung, Neue Fassung 2, 83-121, 171-182.

Collins Dictionary of the English Language. London: Collins, 1979.

Dagut, M. 1978. Hebrew-English Translations. A linguistic antalysis of some semantic problems. Haifa: The University of Haifa.

Dagut, M. 1981. "Semantic 'voids' as a problem in the translation process", Poetics Today, 2 , $4,61.71$.

DTV-Lexikon: Ein Konversationslexikon in 20 Bänden. Deutscher Taschenbuch Verlag: München, 1966.

Duden: das Grosse Wörterbuch der deutschen Sprache. Mannheim: Duden Verlag.

Hammer, W. 1974. Adolf Hitler - ein Prophet unserer Zeit? München: Delph'sche Verlagsbuchhandlung. 
http://spilplus.journals.ac.za/

Hitler, A. 1939. Mein Kampf. Berlin: Deutscher Verlag

Hitler, A. 1969. Mein Kampf, with an introduction by D.C. Watt. Translated by R. Manheim. London: Hutchinson.

Langenscheidts Enzyklopädisches Wörterbuch. Berlin: Langenscheidt,1975.

Muret-Sanders encyclopädisches Wörterbuch der englischen und deutschen Sprache. Berlin: Langenscheidtsche Verlagsbuchhandlung, no year.

Rabin, C 1958. "The linguistics of translation", in A.H. Smith (ed): Aspects of Translation. London: Secker and Warburg, 123-145.

Sapir, E. 1949. Language. New York: Harcourt, Brace and Co.

Sejdel, E. and I. Seidel-Slotty 1961. Sprachwandel im dritten Reich. Halle: VEB Verlag Sprache und Literatur.

Smit, M. 1990. Translating culture-bound terms: an analysis in terms of semantic voids. Unpublished M.A.-thesis, University of Stellenbosch.

Smith, A.H. (ed.): Aspects of Translation. London: Secker and Warburg.

Trübners Deutsches Wörterbuch. Berlin; Walter de Gruyter, 1956.

Wahrig Deutsches Wörterbuch. München: Verlagsgruppe Bertelsmann, 1987.

Wildhagen \& Héraucourt English-German, German-English Dictionary. Wiesbaden: Brandstetter Verlag, 1963. 